\title{
Safety of antipsychotics in people with intellectual disability
}

Valeria Frighi, Matthew T. Stephenson, Alireza Morovat, lain E. Jolley, Marialena Trivella, Christina A. Dudley, Ezhil Anand, Sarah J. White, Christina V. Hammond, Rena A. Hockney, Beryl Barrow, Rehana Shakir and Guy M. Goodwin

\section{Background}

Despite frequent use, little is known about the metabolic and endocrine side-effects of antipsychotics in individuals with intellectual disability.

\section{Aims}

To compare indices of obesity, glucose, lipids and prolactin between antipsychotic-treated and antipsychotic-naive individuals with intellectual disability and also between participants with intellectual disability and controls from the general population.

\section{Method}

Observational study comparing 138 antipsychotic-treated and 64 antipsychotic-naive participants with intellectual disability in one National Health Service trust with general population controls.

\section{Results}

Antipsychotic treatment comprised: risperidone $48 \%$, olanzapine $18 \%$, thioxanthenes $10 \%$, other $24 \%$; monotherapy $95 \%$ of participants; mean treatment duration 8 years; median daily chlorpromazine equivalent dose $108 \mathrm{mg}$ (range 16-667). Metabolic indices were the same or more favourable in the intellectual disability group than the general population control group but overweight/obesity and type 2 diabetes were more prevalent in the women in the intellectual disability group than the control group. Metabolic indices were similar, statistically or clinically, between the antipsychotic-treated and the antipsychotic-naive groups but there was a non-significant trend towards a higher rate of type 2 diabetes in the antipsychotic group. A total of $100 \%$ and $70 \%$ of participants on amisulpride/sulpiride and risperidone respectively had hyperprolactinaemia, with secondary hypogonadism in $77 \%$ and $4 \%$ of affected women and men.

\section{Conclusions}

Antipsychotics, on average, did not increase metabolic risk, although the existence of a susceptible subgroup at risk of diabetes cannot be excluded. Some antipsychotics induced hyperprolactinaemic hypogonadism, requiring active management. However, our findings suggest that antipsychotics at the low doses routinely prescribed for people with intellectual disability are generally safe in relation to metabolic adverse effects, even if efficacy remains poorly defined.

\section{Declaration of interest}

V.F. has received a donation of drug supplies from Bristol-Myers Squibb (BMS) for a trial sponsored by the National Institute of Health Research. G.M.G. has held grants from Sanofi-Aventis and Servier and has received honoraria for speaking from AstraZeneca, BMS, Eisai, Lundbeck, Sanofi-Aventis and Servier, and for advice from AstraZeneca, Boehringer-Ingelheim, BMS, Cephalon, Eli Lilly, Lundbeck, P1vital, Roche, Sanofi-Aventis, Servier and wyeth.
Antipsychotic agents are the psychotropic drugs most frequently prescribed in individuals with intellectual disability (referred to as learning disability by UK health services). ${ }^{1,2}$ Usual indications are comorbid functional psychosis or, more frequently, challenging behaviour. About $25-30 \%$ of all individuals with intellectual disability using services regularly receive antipsychotics $^{1,2}$ rising to $48 \%$ of those with challenging behaviour. ${ }^{3}$ Recent concerns have focused on the inadequate definition of challenging behaviour and the relative absence of controlled evidence for efficacy. ${ }^{4-6}$ There is also an important risk of harm because antipsychotics can induce hyperglycaemia, hyperlipidaemia, obesity and hyperprolactinaemia. ${ }^{7}$ People with intellectual disability are less likely to identify relevant medical symptoms accurately and are less amenable to routine blood testing. Hence such adverse effects carry a particular and enhanced threat to their health.

Although the metabolic and endocrine complications of antipsychotic treatment have been extensively investigated for people with severe mental illness, objective data in the intellectual disability population is limited to one study of 41 participants on metabolic side-effects, ${ }^{8}$ one study on hyperprolactinaemia ${ }^{9}$ and two other studies, which reported both weight and prolactin levels. ${ }^{10,11}$ This lack of data is confirmed, within a clinical setting, by a recent audit showing that only $3 \%$ of individuals with intellectual disability starting an atypical antipsychotic and 1\% during follow-up had undergone monitoring of blood glucose, lipids and body weight. ${ }^{12}$ In this paper we describe the first study on the metabolic and endocrine profiles of a representative intellectual disability cohort compared with a general population control group, and between participants with intellectual disability on antipsychotics and those who were antipsychotic naive.

\section{Method}

The Oxford Learning Disabilities Study was a cross-sectional observational study, approved by the regional ethics committee: all individuals aged 18-70 years on regular antipsychotic treatment or antipsychotic naive under the care of the Oxfordbased psychiatrists of the Ridgeway Partnership (Oxfordshire Learning Disability National Health Service (NHS) Trust) were eligible. The Oxford Biobank cohort ${ }^{13}$ (OBB, 1396 participants) served as a control group. This is a randomly selected, locally derived general population sample from Oxfordshire with no known medical history, hence antipsychotic naive, on which anonymised biochemical, anthropometric, lifestyle and genetic 
data have been collected. The unselected general population sample of over 9000 participants of the Health Survey for England (HSE) $2006^{14}$ was used as a control for data not available from the OBB (prevalence of diabetes, HbAlc).

Capacity was assessed as outlined in the Mental Capacity Act 2005, Code of Practice. ${ }^{15}$ Written informed consent was given by individuals who were capacitous. Those assenting (but formally incapacitous) were only entered into the study after unanimous agreement was obtained that inclusion in the study was in the individual's best interest from key people in the person with intellectual disability's circle of care (which included one or more carer and/or relative). Participants were visited at home by a study nurse, who took consent, completed a questionnaire on family, medical and drug history and lifestyle variables (diet, alcohol, smoking, exercise levels), and measured height and weight for body mass index (BMI), waist circumference and skinfold thickness for body fat distribution and blood pressure. A fasting blood sample was taken for glucose, glycated haemoglobin (HbAlc), lipids, insulin, prolactin, oestradiol, testosterone, gonadotrophins, free thyroxine (T4), thyroid- stimulating hormone (TSH), liver function tests, creatinine, and a full blood count. Glucose was measured by hexokinase, HbAlc by highperformance liquid chromatography (HPLC), triglycerides by standard glycerol-phosphate method, cholesterol by cholesterol esterase with direct measurement of high-density lipoprotein (HDL) cholesterol and low-density lipoprotein (LDL) cholesterol calculated by the Friedewald's formula. ${ }^{16}$ Hormones were measured by immunoassay on a multianalyser (ADVIA Centaur, Bayer Diagnostics). The insulin resistance index (HOMA-IR) was calculated according to the Homeostasis Model Assessment computer model (http://www.dtu.ox.ac.uk/ homacalculator/index.php).

Diagnoses were made on review of case notes and based on DSM-IV criteria. ${ }^{17}$ The daily chlorpromazine equivalent dose was calculated for comparison with published data for phenothiazines, thioxanthenes, haloperidol, sulpiride, risperidone, olanzapine, quetiapine and aripiprazole. ${ }^{18,19}$

\section{Statistical analyses}

Means (standard deviations) or medians (ranges) of continuous variables were compared by independent samples $t$-tests or Mann-Whitney's test and rates by Fisher's exact test or chisquared. A logistic regression model adjusted for age, gender, BMI, waist and exercise levels was used to compare the risk of a raised fasting plasma glucose (FPG $\geqslant 5.6 \mathrm{mmol} / \mathrm{l}$ ) between the antipsychotic-treated and the antipsychotic-naive group and between the participants with intellectual disability (intellectual disability group) and the OBB participants (OBB control group). The study had $80 \%$ power for a difference of $0.5 \mathrm{mmol} / \mathrm{l}$ in FPG and $0.5 \%$ in HbAlc. Analyses were carried out on SPSS (v.14) and STATA (v.10) for Windows.

The metabolic and anthropometric data from participants with diabetes on hypoglycaemic therapy were not included in the comparisons of the antipsychotic-treated $v$. antipsychoticnaive groups. All participants with diabetes were included in the prolactin-related analyses.

\section{Results}

Of 349 potentially eligible individuals identified, $213(61.0 \%)$ participated in the study. A total of $6 \%$ were excluded for psychiatric reasons, $1 \%$ for medical ones and $31 \%$ either refused or the carers refused. Eleven people were subsequently excluded because miscellaneous conditions confounded interpretation of the results (Fig. 1).
We report data on 202 participants with intellectual disability (mean age 42.1 (s.d. =12.8), 52\% men, $48 \%$ women), $62 \%$ of whom were capacitous. Of these $94 \%$ were of European ethnicity, $14 \%$ were smokers and $22 \%$ reported some alcohol intake. Almost all were living in sheltered accommodation. A total of $83 \%$ agreed to a blood sample and $93 \%$ to physical measurements. Skinfold measurements were resisted by many participants and the data were of insufficient quality for analysis.

A total of $48 \%$ of the participants had mild, $30 \%$ moderate, $17 \%$ severe and $5 \%$ profound DSM-IV mental retardation. In $76(38 \%)$ of the participants the intellectual disability was associated with a known condition, most frequently autistic disorder and Down syndrome $(27 \%$ and $22 \%$ of those with a known diagnosis). The rest had a wide range of disorders, including chromosomal abnormalities; $36 \%$ had epilepsy. Participants with mild intellectual disability were overrepresented as some carers were reluctant to enter more severely ill people in the study because of a fear they might become too distressed.

Psychiatric diagnoses by degree of intellectual disability are shown in Table $1 ; 64 \%$ of the total study participants had a concomitant psychiatric disorder, most frequently depression (18\%), schizophrenia and other psychotic disorders (17\%), autistic disorder (10\%), bipolar mood disorder (7\%), anxiety $(6 \%)$, attention-deficit hyperactivity disorder (1\%) and other conditions.

Of the total sample $138(68 \%)$ were on antipsychotics and 64 (32\%) were antipsychotic naive. Eighty participants (58\%) in the antipsychotic-treated group had challenging behaviour, which was the commonest reason for the prescription. There were more men $(59 \%)$ in the antipsychotic-treated and more women $(61 \%)$ in the antipsychotic-naive group. In the whole study group, $27 \%$ of the participants had a diagnosis of challenging behaviour only, in the absence of psychiatric disorders.

Of the 202 participants, $97 \%$ were on one or more psychotropic agents, with a mean of 2.0 drugs per participant (1.4 excluding anti-epileptics). In total $68 \%$ were on antipsychotics, $42 \%$ on antidepressants, $39 \%$ on anti-epileptics, $25 \%$ on benzodiazepines (generally 'as required' rather than regularly), $2 \%$ on non-benzodiazepine hypnotics and $1 \%$ on lithium.

Of the 138 antipsychotic-treated participants, $48 \%$ were on risperidone, $18 \%$ on olanzapine, $10 \%$ on thioxanthenes, $9 \%$ on chlorpromazine or other first-generation phenothiazines, $9 \%$ on quetiapine, $7 \%$ on amisulpride or sulpiride, $4 \%$ on haloperidol, $2 \%$ on aripiprazole and $1 \%$ on clozapine. The

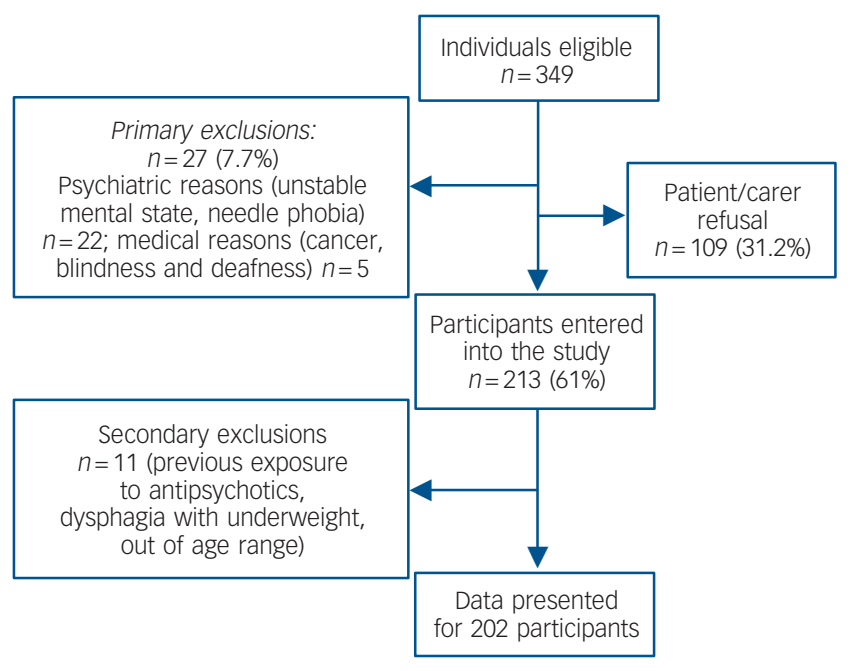

Fig. 1 Flow chart of participants. 
Table 1 Psychiatric diagnoses by degree of intellectual disability

\begin{tabular}{|lccc|} 
& & & $\%$ \\
\cline { 2 - 4 } & $\begin{array}{c}\text { Mild intellectual } \\
\text { disability }(n=97)\end{array}$ & $\begin{array}{c}\text { Moderate intellectual } \\
\text { disability }(n=61)\end{array}$ & $\begin{array}{c}\text { Severe or profound intellectual } \\
\text { disability }(n=44)\end{array}$ \\
\hline Schizophrenia/schizoaffective/psychotic disorders & 28 & 7 & 4 \\
\hline Depression & 24 & 16 & 2 \\
\hline Bipolar mood disorder & 7 & 8 & 3 \\
\hline Anxiety disorders & 7 & 15 & - \\
\hline Autistic disorder & 4 & - & - \\
\hline Dementia & 7 & - & - \\
\hline Obsessive-compulsive disorder & 3 & 1 & - \\
\hline Attention-deficit hyperactivity disorder & 2 & - & - \\
\hline Panic disorder & 2 & - & - \\
\hline Personality disorders & 2 & - & - \\
\hline Asperger syndrome & 1 & & - \\
\hline
\end{tabular}

\begin{tabular}{|c|c|c|c|}
\hline & $\begin{array}{l}\text { Participants on antipsychotics, } \\
\qquad n(\%)(n=138)\end{array}$ & $\begin{array}{l}\text { Median daily dose, mg } \\
(\% \text { maximum daily dose })^{a}\end{array}$ & Dose range, $\mathrm{mg}$ \\
\hline Risperidone & $66(47.8)$ & $2(12.5)$ & $0.5-8$ \\
\hline Olanzapine & $25(18.1)$ & $7.5(37.5)$ & $2.5-20$ \\
\hline Zuclopenthixol $^{\mathrm{b}}$ & $13(9.4)$ & $18(21)$ & $4-50$ \\
\hline Phenothiazines $^{c}$ & $12(8.7)$ & $50(5)$ & $25-375$ \\
\hline Quetiapine & $12(8.7)$ & $200(27)$ & $50-500$ \\
\hline Amisulpride & $8(5.8)$ & 225 (19) & 50-1200 \\
\hline Haloperidol & $6(4.3)$ & $3.25(11)$ & $05-15$ \\
\hline Aripiprazole & $3(2.2)$ & $10(33)$ & $5-30$ \\
\hline Clozapine & $1(0.7)$ & 400 (44) & $N A^{d}$ \\
\hline Flupentixol $^{\mathrm{b}}$ & $1(0.7)$ & $1.4(2)$ & $N A^{d}$ \\
\hline Sulpiride & $1(0.7)$ & $500(21)$ & $N A^{d}$ \\
\hline Chlorpromazine equivalent dose & & $108(11)$ & $16-667$ \\
\hline On one antipsychotic & $131(94.9)$ & & \\
\hline On two antipsychotics & $7(5.1)$ & & \\
\hline \multicolumn{4}{|c|}{$\begin{array}{l}\text { a. Maximum daily dose as recommended for psychoses in the British National Formulary } y^{20} \text { (risperidone: } 16 \mathrm{mg} \text {, olanzapine } 20 \mathrm{mg} \text {, zuclopenthixol } 86 \mathrm{mg} \text {, chlorpromazine } 1 \mathrm{~g} \text {, } \\
\text { quetiapine } 750 \mathrm{mg} \text {, amisulpride } 1200 \mathrm{mg} \text {, haloperidol } 30 \mathrm{mg} \text {, aripiprazole } 30 \mathrm{mg} \text {, clozapine } 900 \mathrm{mg} \text {, flupentixol } 57 \mathrm{mg} \text {, sulpiride } 2400 \mathrm{mg} \text { ). } \\
\text { b. Two- or four-weekly dose divided by number of days. } \\
\text { c. Chlorpromazine, trifluoperazine: dose expressed as chlorpromazine equivalent. } \\
\text { d. NA, not applicable: only one participant on each of these agents. }\end{array}$} \\
\hline
\end{tabular}

majority, 95\%, were on one antipsychotic alone, $5 \%$ on two. Median duration of antipsychotic use was 8 years (range 0.547 ), the median daily chlorpromazine equivalent dose was $108 \mathrm{mg}$ (range 16-667, Table 2).

\section{Anthropometric and metabolic indices}

In the comparison between the intellectual disability and the OBB control group, the mean BMI was significantly higher in women in the intellectual disability group $(31.0 \quad($ s.d.=6.5) $\quad v .25 .6$ (s.d. =4.7), $P<0001)$, but it was similar between the men $(27.5$ $($ s.d. $=6.0)$ v. 26.8 (s.d. $=4.0), P=0.30$, Table 3$)$. Waist circumference was higher in the intellectual disability group $(98.1($ s.d. $=15.0) v$. 93.7 (s.d. $=11.2) \mathrm{cm}, P<0.01$ for men and $99.2($ s.d. $=15.2) v .81 .3$ (s.d. $=11.5) \mathrm{cm}, P<0.001$ for women). Prevalence of overweight and obesity was higher in the women in the intellectual disability group than those in the OBB control group $(81.2 \%$ v. $45.9 \%$, $P<0.001$ ), whereas there was no statistically significant difference between the men $(64.0 \%$ v. $64.8 \%, P=0.878)$. The $81.2 \%$ prevalence of overweight and obesity in the intellectual disability group women was also higher than in the HSE control group women of a similar age, where it was $54 \%$, whereas the $64 \%$ prevalence for the intellectual disability group men was similar to the $68 \%$ rate reported in the HSE control group men $(P=0.385)$.

Although both the men and the women in the intellectual disability group were more sedentary than their general population counterparts $(P<0.001$ for both), as assessed by a standardised questionnaire exploring weekly routine physical activity, the women in the intellectual disability group were also more sedentary than the men in this group $(P<0.001)$. This could partly explain the high BMI of the women, particularly as there was no difference in the prevalence of syndromes associated with obesity, such as Down syndrome, between women and men.

When comparing the antipsychotic-treated and the antipsychotic-naive groups, BMI did not differ between the groups either in men (27.4 (s.d.=5.4) v. 27.6 (s.d.=7.9), $P=0.895)$ or in women (31.3 (s.d.=6.1) v. 29.9 (s.d.=7.2), $P=0.374)$. Waist circumference was also similar between the two groups (98.9 (s.d.=14.2) v. 93.9 (s.d. =18.0) cm, $P=0.266$ for the men, and 100.8 (s.d.=14.5) v. $95.4($ s.d. $=16.3) \mathrm{cm}$, $P=0.395$ for the women), as was the prevalence of overweight and obesity ( $84 \%$ v. $79 \%, P=0.523$ in women and $65 \%$ v. $59 \%$, $P=0.592$ in men). 


\begin{tabular}{|c|c|c|c|c|}
\hline & $\begin{array}{l}\text { Total intellectual disability } \\
\text { group }(n=202)\end{array}$ & $\begin{array}{l}\text { On antipsychotics } \\
\qquad(n=138)\end{array}$ & $\begin{array}{l}\text { Antipsychotic naive } \\
\qquad(n=64)\end{array}$ & Control group \\
\hline Age, years: mean (s.d.) & $42.1(12.8)$ & $41.6(13.4)$ & $42.6(12.4)$ & $41.5(5.8)$ \\
\hline \multicolumn{5}{|l|}{ Gender, \% } \\
\hline Men & 52 & 59 & 39 & 51 \\
\hline Women & 48 & 41 & 61 & 49 \\
\hline \multicolumn{5}{|l|}{ BMI, kg/m²: mean (s.d.) } \\
\hline Males & $27.5(6.0)$ & $27.4(5.4)$ & $27.6(7.9)$ & $26.8(4.0)$ \\
\hline Females & $31.0(6.5)^{b}$ & $31.3(6.1)$ & $29.9(7.2)$ & $25.6(4.7)$ \\
\hline \multicolumn{5}{|l|}{ Waist, cm: mean (s.d.) } \\
\hline Males & $98.1(15.0)^{\mathrm{c}}$ & $98.9(14.2)$ & $93.9(18.0)$ & $93.7(11.2)$ \\
\hline Females & $99.2(15.2)^{d}$ & $100.8(14.5)$ & $95.4(16.3)$ & $81.3(11.5)$ \\
\hline Fasting plasma glucose, mmol/l: mean (s.d.) & $5.2(1.2)$ & $5.0(0.6)$ & $4.9(0.7)$ & $5.2(0.6)$ \\
\hline HbA1c, \%: mean (s.d.) & $5.4(0.7)$ & $5.3(0.4)^{\mathrm{e}}$ & $5.2(0.3)$ & $5.4(0.2)$ \\
\hline Total cholesterol, mmol/l: mean (s.d.) & $5.1(1.1)^{f}$ & $5.1(1.1)$ & $5.1(1.1)$ & $5.4(1.0)$ \\
\hline HDL cholesterol, mmol/l: mean (s.d.) & $1.3(0.4)$ & $1.3(0.4)$ & $1.4(0.3)$ & $1.4(0.3)$ \\
\hline LDL cholesterol, mmol/l: mean (s.d.) & $3.1(0.9)^{f}$ & $3.2(0.9)$ & $3.1(0.9)$ & $3.5(0.9)$ \\
\hline Total/HDL cholesterol: mean (s.d.) & $4.1(1.3)$ & $4.2(1.1)$ & $3.9(1.6)$ & $4.2(1.3)$ \\
\hline Triglycerides, mmol/l: mean (s.d.) & $1.4(1.0)$ & $1.4(0.7)$ & $1.4(1.3)$ & $1.2(0.75)$ \\
\hline Insulin, pmol/l: median (range) & $70.0(8-493)^{f}$ & $73.0(15-475)$ & $69.0(8-493)$ & \\
\hline Insulin resistance index: mean (s.d.) & $1.6(1.1)$ & $1.6(1.0)$ & $1.7(1.3)$ & \\
\hline \multicolumn{5}{|l|}{ Type 2 diabetes, \% } \\
\hline All & 4.8 & $7.4^{\mathrm{g}}$ & 0 & 3.0 \\
\hline Men & 2.2 & 4.6 & 0 & 3.8 \\
\hline Women & $7.9^{\mathrm{h}}$ & 11.6 & 0 & 2.2 \\
\hline \multicolumn{5}{|c|}{$\begin{array}{l}\text { BMI, body mass index; HDL, high-density lipoprotein; LDL, low-density lipoprotein. } \\
\text { a. Comparisons are between individuals in the antipsychotic-treated } v \text {. antipsychotic-naive intellectual disability group and total intellectual disability group } v \text {. general population } \\
\text { group. Control data are from the Oxford Biobank (OBB) cohort }(n=1396) \text { except for HbA1C and type } 2 \text { diabetes prevalence data, which have been obtained from the Health } \\
\text { Survey for England (HSE) age- and gender-matched population }(n=9352 \text { ). } \\
\text { b. } P<0.001 \text { (intellectual disability } v \text {. OBB women). } \\
\text { c. } P<0.01 \text { (intellectual disability } v \text {. OBB men). } \\
\text { d. } P<0.001 \text { (intellectual disability } v \text {. OBB women). } \\
\text { e. } P<0.01 \text { (antipsychotic-treated } V \text {. antipsychotic-naive participants). } \\
\text { f. } P<0.001 \text { (intellectual disability } v \text {. OBB participants). } \\
\text { g. } P=0.052 \text { (antipsychotic-treated } V \text {. antipsychotic-naive participants). } \\
\text { h. } P=0.0106 \text { (intellectual disability } v \text {. HSE women). }\end{array}$} \\
\hline
\end{tabular}

The intellectual disability group had a significantly lower total cholesterol (5.1 (s.d. =1.1) v. $5.4($ s.d. $=1.0), P<0.001)$ and LDL cholesterol $(3.1$ (s.d. $=09)$ v. 3.5 (s.d. $=0.9), P<0.001)$ compared with those in the OBB control group, while FPG, triglycerides and HDL cholesterol were similar. A logistic regression model adjusted for age, gender, BMI, waist and exercise levels, which excluded the participants who had diabetes at entry to the study, showed our intellectual disability group to be less likely to have an FPG level in the hyperglycaemic range $(>5.5 \mathrm{mmol} / \mathrm{l})$ than those in the OBB control group (adjusted odds ratio $(\mathrm{OR})=0.44, P<0.05$, $95 \%$ CI $0.25-0.75$ ). The mean HbA1c of $5.4 \%$ (s.d. $=0.7$ ) (International Federation of Clinical Chemistry (IFCC) $36 \mathrm{mmol} / \mathrm{mol}$ (s.d. =7)) found in the whole study group was virtually identical to the HbAlc of $5.4 \% \quad$ (s.d. $=0.2 \%$, IFCC $36 \mathrm{mmol} / \mathrm{mol}$ $($ s.d. =2)) of the general population sample of similar age in the HSE control group.

In the comparison between the antipsychotic-treated and the antipsychotic-naive group mean FPG levels were not different $(5.0$ (s.d. $=0.6)$ v. 4.9 (s.d. $=0.7) \mathrm{mmol} / \mathrm{l}, P=0.559)$, nor were total, HDL cholesterol, LDL cholesterol, total/HDL cholesterol ratio, triglycerides, insulin or the insulin resistance index. There was no difference in the risk of a raised $(>5.5 \mathrm{mmol} / \mathrm{l}) \mathrm{FPG}$ between the two groups. The HbAlc levels were significantly higher in the antipsychotic-treated group but the absolute difference was too small to be considered clinically significant $(5.3 \%$ (s.d. $=0.4)$ v. $5.2 \%$ (s.d. $=0.3$ ), $P<001,95 \%$ CI of the difference $0.044-0.290$, IFCC $34($ s.d.=6) v. $33($ s.d. $=4) \mathrm{mmol} / \mathrm{mol})$.

\section{Type 2 diabetes}

At study entry, there were seven participants known to have developed type 2 diabetes after exposure to antipsychotic drugs. Another participant on antipsychotics was diagnosed as having diabetes during the study. Prevalence of type 2 diabetes was $7.4 \%$ in the antipsychotic-treated group and nil in the antipsychotic-naive group, an apparent difference albeit of borderline statistical significance $(P=0.052)$.

For the comparison of intellectual disability $v$. age- and gender-matched general population participants, prevalence of type 2 diabetes was defined similarly to the HSE control group as the percentage of participants with previously known type 2 diabetes out of the whole of the study group. Diabetes prevalence was similar in the men $(2.2 \% v .3 .8 \%, P=0.584)$ but was higher in the women in the intellectual disability group than in women in the HSE control group $(7.9 \%$ v. $2.2 \%, P=0.0106)$ of similar age.

Of the eight participants with type 2 diabetes diagnosed after initiation of antipsychotic treatment, three were currently on olanzapine and one each on risperidone, amisulpride, zuclopenthixol, haloperidol and trifluoperazine; all but one had been exposed to various antipsychotics over the years. Mean antipsychotic treatment duration before diagnosis of diabetes was 9.7 years (s.d. $=7.7$, range 2-20). Mean age at diagnosis of diabetes was 42.7 years (s.d.=8.8). Of the participants with diabetes, one had a history of developing uncontrolled diabetes 


\begin{tabular}{|c|c|c|c|c|c|}
\hline & $\begin{array}{l}\text { Antipsychotic naive } \\
\qquad(n=64)\end{array}$ & $\begin{array}{l}\text { On antipsychotics } \\
\qquad(n=138)\end{array}$ & $\begin{array}{l}\text { Risperidone } \\
\quad(n=66)\end{array}$ & $\begin{array}{l}\text { Amisulpride/sulpiride } \\
\qquad(n=9)\end{array}$ & $\begin{array}{l}\text { Other antipsychotic } \\
\qquad(n=63)\end{array}$ \\
\hline \multicolumn{6}{|c|}{ Prolactin mU/l, median (range) } \\
\hline Males & $219(111-549)$ & $365(120-1476)$ & $500(180-1476)$ & $906(423-1325)$ & $235(120-662)$ \\
\hline Females & $228(88-2075)$ & $533(103-5959)$ & $1078(192-5959)$ & $1835(1358-2235)$ & $280(144-969)$ \\
\hline \multicolumn{6}{|c|}{ Hyperprolactinaemia, ${ }^{\text {a } \%}$} \\
\hline Males & 15 & 44 & 70 & 100 & 7 \\
\hline Females & 10 & 47 & 72 & 100 & 9 \\
\hline \multicolumn{6}{|c|}{ Hyperprolactinaemic hypogonadism, ${ }^{\text {b } \%}$} \\
\hline Males & 0 & 3 & 4 & 0 & 0 \\
\hline Females & 0 & 77 & 75 & 80 & 0 \\
\hline \multicolumn{6}{|c|}{$\begin{array}{l}\text { a. Prolactin }>375 \mathrm{mU} / \mathrm{in} \text { men and }>620 \mathrm{mU} / \mathrm{l} \text { in women. } \\
\text { b. Hyperprolactinaemic hypogonadism is expressed as the percentage of participants who were hyperprolactinaemic that developed hypogonadism as a complication of } \\
\text { hyperprolactinaemia. Participants in whom the diagnosis of hypogonadism is impossible, namely those on exogenous sex steroids, have been excluded from this analysis. }\end{array}$} \\
\hline
\end{tabular}

when quetiapine was added to his haloperidol treatment and another one experienced near normalisation of glucose indices when her treatment was changed from olanzapine to risperidone.

\section{Risk factors for diabetes}

A family history was obtained for $68 \%$ of participants. This was positive for diabetes in at least one first- or second-degree relative in $86 \%$ of those with diabetes and in $41 \%$ of those participants without diabetes $(P<0.05)$. South Asian or African-Caribbean ethnicity was $11 \%$ in those with and $4.8 \%$ in those without diabetes $(P=0.377)$. Participants with diabetes tended to be older (46.3 (s.d. $=7.0)$ v. $41.9($ s.d. $=13.1)$ years, $P=0.319)$ and more obese (BMI 30.8 (s.d. $=4.8)$ v. 28.8 (s.d. $=6.3$ ), $P=0.355$ ) than those without diabetes.

\section{Prolactin, gonadal function and bone mineral density}

Hyperprolactinaemia (prolactin $>375 \mathrm{mU} / \mathrm{l}$ in men and $>620 \mathrm{mU} / \mathrm{l}$ in women) was present in $45 \%$ of participants on antipsychotics and in $12.5 \%$ of those who were antipsychotic naive (Table 4 ). Prevalence was much higher in individuals on risperidone and amisulpride/sulpiride, $70 \%$ and $100 \%$ respectively. Most participants with hyperprolactinaemia not explained by risperidone, amisulpride or sulpiride, whether in the antipsychotic or antipsychotic-naive group, were taking other drugs that can cause prolactin elevation such as antidepressants (e.g. citalopram), peripheral dopamine antagonists or proton pump inhibitors.

Of the 21 women with antipsychotic-induced hyperprolactinaemia, 8 premenopausal women were taking exogenous sex hormones. Of the remaining 13 women, 10 were hypogonadal, as defined by a history of amenorrhoea or by gonadotrophins below the menopausal range in pre- and postmenopausal women respectively. Of 27 men with hyperprolactinaemia, only 1 was hypogonadal, as defined by a testosterone level below the normal range. The prolactin levels in women who were hypogonadal ranged between 1083 and $5959 \mathrm{mU} / \mathrm{l}$ and in the man who was hypogonadal it was $1105 \mathrm{mU} / \mathrm{l}$. Eight of nine patients with hyperprolactinaemic hypogonadism who underwent a dual-energy $\mathrm{x}$ ray absorptiometry scan had decreased bone mineral density ( $\mathrm{T}$ score $\leqslant 1.0)$.

\section{Discussion}

\section{Main findings}

This is the first study to compare metabolic and endocrine parameters in a representative community-dwelling intellectual disability population with a locally recruited population of controls and between individuals naive to antipsychotic drugs and those taking them for psychosis or challenging behaviour. The study was widely inclusive, being open to all patients aged $18-70$ in a single NHS trust under psychiatric care, thus it is very likely to have mirrored current routine clinical practice. It is extremely difficult to collect data of this sort in an intellectual disability population so the $61 \%$ participation rate is a considerable achievement. Failure to participate was primarily for arbitrary reasons relating to carer agreement rather than any significant clinical bias. In the antipsychotic-treated group, monotherapy was the rule (95\% of people) and doses were generally low, both compared with schizophrenia ${ }^{21,22}$ and with a previous study in people with intellectual disability, in which the mean chlorpromazine equivalent dose was $372 \mathrm{mg}$ (range 20-4067), ${ }^{23}$ more than three times the median $108 \mathrm{mg}$ (range 16-667) found in our study. Almost half of the participants were on risperidone, which is in line with the limited evidence for benefit in the treatment of challenging behaviour. ${ }^{24,25}$

Comparisons with the general population showed that glucose and lipid parameters were on average the same or even more favourable in the intellectual disability group. This contrasts with findings in individuals with severe mental illness, in which metabolic abnormalities are highly prevalent. ${ }^{26}$ Moreover, there was a paucity of other metabolic and cardiovascular risk factors such as alcohol excess, smoking or an atherogenic diet, which are common in the general population, and even more so in populations with severe mental illness. Nevertheless, in women, not men, prevalence of overweight/obesity and of type 2 diabetes were markedly higher in the intellectual disability group. Whereas the favourable lipid profile of our intellectual disability group could be explained by a healthy diet provided in sheltered accommodation and by the other positive lifestyle factors, the highly sedentary lifestyle led by the women in this group could partly explain their high prevalence of obesity, which could be the main determinant for their high rates of diabetes. A higher prevalence of obesity in women with intellectual disability compared with men with intellectual disability and with women in the general population has been previously reported. ${ }^{27,28}$ Moreover, although people with intellectual disability have lower levels of physical activity than participants from the general population, the risk of inactivity is higher in women with intellectual disability than men. ${ }^{28}$

The metabolic profile of participants in the intellectual disability group on antipsychotics was essentially identical to that of those in the group who were antipsychotic naive. It is reassuring that indices of obesity and of glucose and lipid metabolism were not significantly different, statistically or clinically, between the antipsychotic-treated and the antipsychotic-naive individuals. 
The absence of any effect could be due, in part, to the relatively small number of people taking antipsychotics with the highest potential metabolic impact, such as olanzapine and clozapine, and to the generally low doses. All the cases of diabetes occurred in individuals on antipsychotics, but the study was underpowered to estimate differences in prevalence rates with confidence. Although antipsychotics, on average, did not increase metabolic risk, the trend towards a higher prevalence of type 2 diabetes in the antipsychotic-treated group may suggest that a subgroup of individuals are particularly vulnerable to the hyperglycaemic potential of these drugs. This accords with the relatively young age at diagnosis of diabetes and the higher prevalence of a positive family history compared with those without diabetes. However, these individuals did not represent the tip of a metabolic iceberg, given the normal findings in participants without diabetes.

A total of $45 \%$ of antipsychotic-treated participants ( $70 \%$ of those on risperidone, $100 \%$ of those on amisulpride or sulpiride) had hyperprolactinaemia, with secondary hypogonadism in $77 \%$ of affected women but only $4 \%$ of affected men. A raised prolactin was equally frequent in antipsychotic-treated participants of either gender but, as reported by previous studies, ${ }^{29,30}$ prolactin elevation was more severe in women than men, thus explaining the gender differential in the prevalence of hypogonadism. Clinically significant hyperprolactinaemia, causing secondary hypogonadism, was exclusively seen in participants on risperidone, amisulpride or sulpiride even at low doses. As in earlier studies, ${ }^{31,32,33}$ hyperprolactinaemic hypogonadism was generally accompanied by loss of bone mineral density. This iatrogenic complication will summate with other risk factors for bone pathology in intellectual disability, such as primary hypogonadism, anti-epileptic treatment and vitamin D deficiency, and could partly explain the high risk for osteoporosis and fractures seen in these indivduals. ${ }^{34,35,36}$

\section{Strengths and limitations of the study}

This is the only study comparing metabolic and endocrine parameters between antipsychotic-treated and antipsychotic-naive individuals with intellectual disability and between individuals with intellectual disability and the general population. Moreover, its naturalistic setting in one NHS trust and wide inclusion criteria make its results generalisable with a strong degree of confidence. However, despite being a large study compared with others in this population, the sample size was not large enough to allow a robust comparison of diabetes rates between the antipsychotic-treated and the antipsychotic-naive group, something that could possibly explain the borderline statistical difference between the two groups. This problem could only be overcome by a multicentre study.

\section{Implications}

In summary, the Oxford Learning Disabilities Study provides an initial evidence base underpinning the safe use of antipsychotic drugs in the intellectual disability population. Whatever the efficacy of antipsychotic use in relation to challenging behaviour, they are still widely used. This would be difficult to defend in such a vulnerable population if it led to major metabolic side-effects. In fact, our findings offer significant reassurance in relation to cardiovascular and metabolic risk in the intellectual disability population. Nevertheless, there may be potential problems in a susceptible subgroup, hence regular monitoring of blood glucose, lipids and weight ${ }^{37}$ should be instituted when prescribing antipsychotics to people who may already have risk factors for diabetes, and when using antipsychotics with a high metabolic impact.

The study identified hyperprolactinaemia as the commonest side-effect in antipsychotic-treated individuals with intellectual disability and hyperprolactinaemic hypogonadism as a complication of risperidone and amisulpride treatment, leading to bone loss in a population already at risk for osteoporosis and fractures. These findings should lead to screening for and management of hyperprolactinaemic hypogonadism, together with studies to investigate optimal prevention and treatment strategies in the intellectual disability population.

\section{Valeria Frighi, MD, Department of Psychiatry, University of Oxford and Ridgeway Partnership (Oxfordshire Learning Disability NHS Trust), Oxford; Matthew T. \\ Stephenson, MRCPsych, MSysPsych, Ridgeway Partnership (Oxfordshire Learning Disability NHS Trust), Oxford; Alireza Morovat, PhD, RCPath, Department of Clinical Biochemistry, Oxford Radcliffe Hospital NHS Trust, Oxford; Iain E. Jolley, MRCPsych, Ridgeway Partnership (Oxfordshire Learning Disability NHS Trust), Oxford; Marialena Trivella, MSc, DPhil, Department of Health Services Research and Policy, London School of Hygiene and Tropical Medicine, London; Christina A. Dudley, RGN, Oxford Centre for Diabetes, Endocrinology and Metabolism, University of Oxford, Oxford; Ezhil Anand, MMedSci, MRCPsych, Ridgeway Partnership (Oxfordshire Learning Disability NHS Trust); Sarah J. White, RGN, Oxford Centre for Diabetes, Endocrinology and Metabolism, University of Oxford, Oxford; Christina v. Hammond, BSC, Department of Public Health and Primary Care, University of Oxford; Rena A. Hockney, RMN, Department of Psychiatry, University of Oxford; Beryl Barrow, RGN, Oxford Centre for Diabetes, Endocrinology and Metabolism, University of Oxford; Rehana Shakir, MRCPsych, Ridgeway Partnership (Oxfordshire Learning Disability NHS Trust), Oxford; Guy M. Goodwin, DPhil, FMedSci, Department of Psychiatry, University of Oxford, Oxford, UK
of}

Correspondence: Valeria Frighi, Department of Psychiatry, Neurosciences Building, Warneford Hospital, Warneford Lane, Oxford OX3 7JX, UK. Email: valeria.frighi@psych.ox.ac.uk

First received 22 Sep 2010, final revision 2 Apr 2011, accepted 17 May 2011

\section{Funding}

The study was supported by the Baily Thomas Charitable Fund.

\section{Acknowledgements}

We thank all the patients who participated in the study, the carers for their support, and Professor Fredrik Karpe and the NIHR Oxford Biomedical Research Centre for helpful advice and for allowing us to use the Oxford Biobank database. We also thank Dr Susan Manley and Professor Francesco Pezzella for useful comments.

\section{References}

1 Branford D. A study of the prescribing for people with learning disabilities living in the community and in National Health Service care. J Intellect Disabil Res 1994; 38: 577-86.

2 Holden B, Gitlesen JP. Psychotropic medication in adults with mental retardation: prevalence, and prescription practices. Res Dev Disabil 2004; 25: 509-21

3 Kiernan C, Reeves D, Alborz A. The use of anti-psychotic drugs with adults with learning disabilities and challenging behaviour. J Intellect Disabil Res 1995; 39: 263-74.

4 Brylewski J, Duggan L. Antipsychotic medication for challenging behaviour in people with learning disability. Cochrane Database of Systematic Reviews 2004; 2: CD000377.

5 Singh AN, Matson JL, Cooper CL, Dixon D, Sturmey P. The use of risperidone among individuals with mental retardation: clinically supported or not? Res Dev Disabil 2005; 26: 203-18.

6 Tyrer P, Oliver-Africano PC, Ahmed Z, Bouras N, Cooray S, Deb S, et al. Risperidone, haloperidol, and placebo in the treatment of aggressive challenging behaviour in patients with intellectual disability: a randomised controlled trial. Lancet 2008; 371: 57-63.

7 Henderson DC, Doraiswamy PM. Prolactin-related and metabolic adverse effects of atypical antipsychotic agents. J Clin Psychiatry 2008; 69 (suppl 1): $32-44$.

8 McKee JR, Bodfish JW, Mahorney SL, Heeth WL, Ball MP. Metabolic effects associated with atypical antipsychotic treatment in the developmentally disabled. J Clin Psychiatry 2005; 66: 1161-8. 
9 Hellings JA, Zarcone JR, Valdovinos MG, Reese RM, Gaughan E, Schroeder SR. Risperidone-induced prolactin elevation in a prospective study of children, adolescents, and adults with mental retardation and pervasive developmental disorders. J Child Adolesc Psychopharmacol 2005; 15 885-92.

10 Turgay A, Binder C, Snyder R, Fisman S. Long-term safety and efficacy of risperidone for the treatment of disruptive behavior disorders in children with subaverage IQs. Pediatrics 2002; 110: e34.

11 Handen BL, Hardan AY. Open-label, prospective trial of olanzapine in adolescents with subaverage intelligence and disruptive behavioral disorders. J Am Acad Child Adolesc Psychiatry 2006; 45: 928-35.

12 Devapriam J, Anand A, Raju LB, Bhaumik S. Monitoring for metabolic syndrome in adults with intellectual disability on atypical antipsychotic drugs Br J Dev Disabilities 2009; 55 (Pt 1): 3-13.

13 Tan GD, Neville MJ, Liverani E, Humphreys SM, Currie JM, Dennis L, et al. The in vivo effects of the Pro12Ala PPARgamma2 polymorphism on adipose tissue NEFA metabolism: the first use of the Oxford Biobank. Diabetologia 2006; 49: 158-68.

14 Department of Health. Health Survey for England 2006. Department of Health, 2008 (http://www.ic.nhs.uk/pubs/hse06cvdandriskfactors).

15 Department for Constitutional Affairs. Mental Capacity Act 2005 Code of Practice. TSO (The Stationery Office), 2007.

16 Friedewald WT, Levy RI, Fredrickson DS. Estimation of the concentration of low-density lipoprotein cholesterol in plasma, without use of the preparative ultracentrifuge. Clin Chemistry 1972; 18: 499-502.

17 American Psychiatric Association. Diagnostic and Statistical Manual of Mental Disorders (4th edn) (DSM-IV). APA, 1994.

18 Woods SW. Chlorpromazine equivalent doses for the newer atypical antipsychotics. J Clin Psychiatry 2003; 64: 663-7.

19 Taylor D, Paton C, Kervin R. The Maudsley Prescribing Guidelines (9th edn). Informa Healthcare, 2007.

20 British Medical Association, Royal Pharmaceutical Society of Great Britain. British National Formulary (issue 60). BMJ Group and Pharmaceutical Press, 2010.

21 Uchida H, Suzuki DC, Mamo BH, Mulstant BH, Tanabe A, Inagaki A, et al. Effects of age and age of onset on prescribed antipsychotic dose in schizophrenia sectrum disorders: a survey of 1,418 patients in Japan. Am Geriatr Psychiatry 2008; 16: 584-93.

22 Lieberman JA, Stroup TS, McEvoy JP, Swartz MS, Rosenheck RA, Perkins DO, et al. Effectiveness of antipsychotic drugs in patients with chronic schizophrenia. N Engl J Med 2005; 353: 1209-23.

23 Ahmed Z, Fraser W, Kerr MP, Kiernan C, Emerson E, Robertson J, et al. Reducing antipsychotic medication in people with a learning disability. Br J Psychiatry 2000; 176: 42-6.
24 Gagiano C, Read S, Thorpe L, Eerdekens M, Van Hove I. Short- and long-term efficacy and safety of risperidone in adults with disruptive behavior disorders. Psychopharmacol 2005; 179: 629-36.

25 Deb S, Sohanpal SK, Soni R, Lenotre L, Unwin G. The effectiveness of antipsychotic medication in the management of behaviour problems in adults with intellectual disabilities. J Intellect Disabil Res 2007; 51: 766-77.

26 McEvoy JP, Meyer JM, Goff DC, Nasrallah HA, Davis SM, Sullivan L, et al. Prevalence of the metabolic syndrome in patients with schizophrenia: baseline results from the Clinical Antipsychotic Trials of Intervention Effectiveness (CATIE) schizophrenia trial and comparison with national estimates from NHANES III. Schizophr Res 2005; 80: 19-32.

27 Robertson J, Emerson E, Gregory N, Hatton C, Turner S, Kessissoglous, et al. Lifestyle related risk factors for poor health in residential settings for people with intellectual disabilities. Res Dev Disabil 2000; 21: 469-86.

28 Emerson E. Underweight, obesity and exercise among adults with intellectual disabilities in supported accommodation in Northern England. I Intellect Disabil Res 2005; 49: 134-43.

29 Kuruvilla A, Peedicayil J, Srikrishna G, Kuruvilla K, Kanagasabapathy AS. A study of serum prolactin levels in schizophrenia: comparison of males and females. Clin Exp Pharmacol Physiol 1992; 19: 603-6.

30 Bushe C, Yeomans D, Floyd T, Smith SM. Categorical prevalence and severity of hyperprolactinaemia in two UK cohorts of patients with severe mental illness during treatment with antipsychotics. J Psychopharmacol 2008; 22: $56-62$.

31 O'Keane V. Antipsychotic-induced hyperprolactinaemia, hypogonadism and osteoporosis in the treatment of schizophrenia. J Psychopharmacol 2008; 22 : $70-5$.

32 Klibanski A, Neer RM, Beitins IZ, Ridgway EC, Zervas NT, McArthur JW. Decreased bone density in hyperprolactinemic women. N Engl J Med 1980; 303: 1511-4.

33 Greenspan SL, Neer RM, Ridgway EC, Klibanski A. Osteoporosis in men with hyperprolactinemic hypogonadism. Ann Intern Med 1986; 104: 777-82.

34 Hawli $Y$, Nasrallah M, El-Hajj Fuleihan G. Endocrine and musculoskeletal abnormalities in patients with Down syndrome. Nature Rev 2009; 5: 327-34.

35 Schrager S. Epidemiology of osteoporosis in women with cognitive impairment. Ment Retard 2006; 44: 203-11.

36 Vanlint S, Nugent M. Vitamin D and fractures in people with intellectual disability. J Intellect Disabil Res 2006; 50: 761-7.

37 American Diabetes Association, American Psychiatric Association, American Association of Clinical Endocrinologists, North American Association for the Study of Obesity. Consensus development conference on antipsychotic drugs and obesity and diabetes. Diabetes Care 2004; 27: 596-601. 